\title{
The Effects of Librarians' Behavioral Performance on User Satisfaction in Chat Reference Services
}

The purpose of this study was to determine the effective behaviors of reference librarians during the chat reference interview, with particular emphasis given to whether the service users would feel more satisfied when librarians adopt the behaviors recommended in the revised "RUSA Guidelines for Behavioral Performance of Reference and Information Services Providers." The data analyzed for this study consisted of 422 chat reference transaction transcripts and corresponding user surveys obtained from a public library system that participated in a nationwide chat reference consortium. In six of the ten behavioral types observed, the users perceived the service as more satisfying when librarians demonstrated the behaviors suggested in the revised guidelines than when they did not. Five of these behaviors-receptive and cordial listening, searching information sources with or for the patrons, providing information sources, asking patrons whether the question was answered completely, and asking patrons to return when they need further assistance-were revealed as strong predictors of user satisfaction. These findings demonstrated that the RUSA behaviors are effective in increasing user satisfaction, suggesting that the guidelines can continue to be used as an effective tool for both staff training and service as- sessment in chat reference services. This report concludes with recommendations for further improvement of the guidelines and agendas for future research.

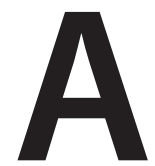
s library users become more comfortable with using the Web for services and to search for information, librarians often have led the way in making reference services available to patrons online. Online real-time chat reference services have become increasingly prevalent in many types and sizes of libraries, and, as with any other library service, it is important to evaluate the effectiveness of, and user satisfaction with, those services. ${ }^{1}$ This research reports the results and conclusions from a case study of a chat reference service intended to assess the usefulness of the 2004 revised "RUSA Guidelines for Behavioral Performance of Reference and Information Services Providers" (hereinafter referred to as "revised guidelines"). ${ }^{2}$ These were originally developed by the Reference and User Services Association (RUSA) in 1996 as behavioral guidelines to support reference staff working at a physical reference desk (hereinafter referred to as "original guidelines"). ${ }^{3}$

The purpose of this study is to:

\section{Nahyun Kwon and Vicki L. Gregory}

Nahyun Kwon is Assistant Professor and Vicki L. Gregory is Professor, School of Library and Information Science, University of South Florida, Tampa. This manuscript was based on a presentation by Kwon, "Assessing the Virtual Reference Success using the Revised RUSA Guidelines for Behavioral Performance of Reference and Information Service Providers," at the 6 th Virtual Reference Desk Conference, Cincinnati, Ohio, November 8-9, 2004. Submitted for review March 11, 2005; revised and accepted for publication May 2, 2006.

Reference \& User Services Quarterly, vol. 47, no. 2, pp. 137-148 (c) 2007 American Library Association. All rights reserved.

Permission granted to reproduce for nonprofit, educational use. 
- investigate, in a series of chat interviews, the extent to which librarians' behaviors reflected those recommended in the revised guidelines;

- assess the influence of those behaviors on user satisfaction; and

- examine the revised guidelines as a useful assessment tool in evaluating the efficacy of a chat reference service.

The results of this study will provide library professionals with a better understanding of the nature of chat reference interviews as well as test the usefulness of the revised guidelines in the context of chat reference services. The results of this study will better elucidate effective teaching methods and techniques for library educators within the area of virtual reference with respect to the reference question negotiation process.

\section{BACKGROUND OF THE STUDY}

\section{The Original Guidelines (1996) and the Revised Guidelines (2004)}

Perhaps one of the most important roles of professional associations is to establish benchmarking standards and develop useful guidelines to assist their members' practice. RUSA has been at the forefront in offering its members such support. Beginning in the 1980s, RUSA began developing reference interview guidelines intended to delineate those librarian behaviors most likely to lead to an effective face-to-face reference interview. This effort resulted in the publication of the "RUSA Guidelines for Behavioral Performance of Reference and Information Services Providers" in 1996. A handful of research studies conducted since that time have consistently indicated that use of the behaviors prescribed in the original guidelines is positively associated with reference success. ${ }^{4}$ The original guidelines thus became widely recognized as the only behavioral guidelines of its kind for reference staff. Besides the fact that the original guidelines were prepared by RUSA, a leading professional association among reference librarians, the continued use of the original guidelines in practice seems to suggest their usefulness as standards for reference staff training as well as performance evaluation.

A revised and extended version of the original guidelines was published in June 2004. This revision reflects the increasing need for behavioral standards that can assist personnel who provide virtual reference services. Maintaining the five-component structure of the original guide- lines (that is, approachability, interest, listening/ inquiring, searching, and follow-up), the revised guidelines subcategorized each of those five components into three settings: general, in-person (physical setting), and remote (virtual settings). The five-component structure is summarized as follows:

- First, approachability refers to behaviors that ensure easy access to the reference staff by lowering barriers to personal assistance. Example behaviors include making instructional and directional signs clear, making the presence of reference assistance visible, and establishing "word" contact with the patrons.

- Second, interest refers to behaviors that exhibit librarians' interest in patron inquiries so that patrons can ask questions without hesitation. Example behaviors include focusing attention on the patron, maintaining and re-establishing "word" contact, and clarifying the scope of the questions.

- Third, listening/inquiring refers to behaviors that exhibit good listening and questioning skills so that librarians can identify patrons' real information needs, which sometimes are buried or poorly expressed. Example behaviors are communicating in receptive and cordial ways, using proper written language, ensuring adequate probing, and rephrasing questions to ensure adequate understanding.

- Fourth, searching includes the application of effective search skills and related behaviors that can enhance searching effectiveness and result in finding accurate answers. Example behaviors include explaining search strategies, escorting patrons in the search process, and providing pointers and information sources.

- Finally, follow-up refers to the behaviors involved in bringing proper closure to the reference transaction. Example behaviors include asking patrons if their questions were completely answered, asking if they need additional information, referring them to alternative sources or agencies if their questions were not answered, and urging patrons to return if they need further assistance.

As described above, the revised guidelines have incorporated many behaviors that pertain specifically to virtual reference. Yet, the core components and ideas remain the same as those set out in the original guidelines prepared for face-to-face reference service practice. 


\section{Librarians'Behavioral Performance during Chat Reference Service}

The body of the reference service literature has consistently emphasized that the quality of the reference interview is an important factor in reference service effectiveness. In their seminal research, Gers and Seward demonstrated that reference librarians' verbal and nonverbal communication skills during the reference interview are crucial in delivering reference services successfully. ${ }^{5}$ This research has had a great affect on the research and the practice of reference services, and has brought attention to the need for pertinent staff training that can provide instruction in, and emphasize the importance of, verbal and nonverbal communication skills in the reference interview. Saxton reported that reference effectiveness was most consistently predicted by the presence of verbal and nonverbal behaviors prescribed in the original guidelines. ${ }^{6}$ Subsequent studies also reported similar findings, substantiating RUSA's initial intent to provide the original guidelines as a service assessment tool. ${ }^{7}$

Yet, many issues remain veiled regarding the interactions between librarians and patrons in virtual space in general, and reference interviews during chat sessions specifically. Some of the important but unanswered questions are:

- How do reference librarians interact with their patrons in chat reference settings?

- Are the interactions in chat reference similar to, or considerably different from, those in traditional reference services?

- What staff behaviors would be most conducive to user satisfaction with chat reference services?

Regarding these questions, some would argue that the interactions between patrons and librarians in chat settings should not be fundamentally different from those involved in the physical reference setting because both ultimately serve the same purpose-resolving information problems by answering questions. In essence, proponents of this position view chat reference as the same service delivered via a different medium, much like the telephone reference service that was new in the 1930s. In contrast, others would contend that the particular mode of virtual communications is the very factor that makes chat reference different from the face-to-face or the telephone reference interview. After all, virtual communication lacks facial, aural, or environmental cues, which are crucial components in the physical reference set- ting, as well as the voice cues that are so crucial to phone reference. $^{8}$

In the absence of clear understanding of the nature of chat reference interactions, identifying effective librarian behaviors in the chat reference interview will be an important first step in helping librarians to achieve higher levels of service performance. In this regard, specific behaviors prescribed in the revised guidelines can be utilized as effective behavioral standards to examine librarians' actual behaviors while answering questions during chat sessions. Thus, the purpose of the present study was to investigate the extent to which the behaviors prescribed in the revised guidelines are observed in chat reference sessions, and whether the presence of those behaviors (hereinafter referred to as "RUSA behaviors") increases user satisfaction with chat reference. For this purpose, three specific research questions were proposed for investigation:

- Research question 1: To what extent is each RUSA behavior observed in chat reference interviews?

- Research question 2: Is user satisfaction with chat reference higher when librarians perform the RUSA behaviors during reference sessions than when they do not?

- Research question 3: Which of the RUSA behaviors performed during chat reference interviews could predict higher user satisfaction?

The findings of the present study will enable us to determine whether the RUSA behaviors can lead to more effective reference services performance. Ultimately, the results of the study will help us to resolve the question of whether the revised guidelines can be effectively used as a pertinent training and service assessment tool for chat reference services.

\section{METHODS}

\section{Setting and Participants}

The present study examined chat reference services delivered through the Broward County public library system, the largest such system in Florida, with thirty-three regional and branch libraries. Since August 2002, the system has used a chat reference service dubbed "24/7 Reference" delivered by the Metropolitan Cooperative Library System (MCLS), an association of libraries located in the greater Los Angeles area funded by a federal Library Services and Technology Act grant. MCLS's 24/7 Reference was merged with Online 
Computer Library Center's (OCLC) QuestionPoint in August 2004.

The data examined for the present study were online chat reference transactions initiated by patrons of the Broward Country library system, along with survey responses submitted by the patrons. While the patrons were mostly users of the Broward County system, the reference staff members who provided the service were from forty-nine library systems across the United States participating in the MCLS 24/7 Reference program. During the six-month duration of the research study, between January and June 2004, a total of 1,387completed or transferred transactions took place. As the intention of this study was to analyze the influence of librarians' behaviors on user satisfaction, only the transactions that had a corresponding completed self-report user satisfaction survey were selected for data analysis. Thus, the total number of transactions analyzed for the present study was 422 , comprising 30.4 percent of the total analyzable transactions.

\section{Coding RUSA Behaviors}

RUSA behaviors refer to the behaviors prescribed in the revised guidelines. These behaviors were coded through the analysis of 422 chat transcripts that show all patron-staff interactions as well as search activities, including co-browsing. Initially, librarians' behaviors were coded against all fortynine items in the revised guidelines, which include all three modes of transactions (general, in-person, and remote). This decision was made because certain items listed under the in-person category

Figure 1. A Coding Scheme of Ten RUSA Behaviors

\section{Five Areas in the Re- vised Guidelines}

1. Approachability

2. Interest

3. Listening/inquiring

4. Searching

5. Follow-up
Ten Behavioral Types Analyzed

Welcoming Using patron names

Interest

Listening

Inquiring

Searching for/with patrons

Offering pointers

Answered?

Referrals

Come back
Corresponding Items in the Revised Guidelines

1.0

IFLA

$2.2,2.6$

$3.1-3.2$

$3.5-3.8$

$4.3,4.6,4.10,4.11$

$4.5,4.9,4.11$

$4.7,5.1,5.9$

$5.4-5.8,5.9$ (remote)

5.2 also were applicable to the chat reference setting (for example, "Accompanies the patrons in the search"). Later, the initial forty-nine items were collapsed into ten types of behaviors after merging similar items together and removing items that were either unobservable or irrelevant for chat reference. For example, some items describe thought processes rather than actual observable behaviors (for example, "recognizes when to refer patrons to a more appropriate guide, database, library, librarian, or other resource [4.8]"). Some behaviors, such as providing information sources, were observed across multiple items (For example, "Offers pointers, detailed search paths [including complete URLs], and names of resources used to find the answer [4.9]" and "Uses appropriate technology [such as co-browsing, scanning, faxing, etc.] to help guide patrons through library resources, when possible [4.11]"). Finally, some items are applicable for physical setting transactions only (for example, "Be mobile [1.7.1]"). Figure 1 displays the final coding scheme that lists ten RUSA behavioral types along with corresponding item numbers in the revised guidelines.

As shown in figure 1, specific items in the five RUSA behavioral areas were coded into ten behavioral types in the present study. Approachability was observed by two behavioral types: welcoming and the use of patrons' name. First, welcoming was coded to be present either when an initial word contact was made (such as "Hi, this is the reference librarian") or when a general welcoming atmosphere was observed from the librarians' written communications. Other than these examples, the revised guidelines do not include many clear behavioral indicators of approachability. Thus, the second behavioral type, the use of patrons' name, was adopted from the Guidelines for Chat Sessions within "IFLA Digital Reference Guidelines"; the assumption here is that the behavior could lower the patron's emotional barriers and thus enhance the librarian's approachability. ${ }^{9}$ Currently, there is no consensus about the effectiveness of using a patron's name during the chat session. Some think it is effective because it could make the reference interview more personable and approachable. Others think that it may intrude upon personal privacy. By observing its use, we will be able to determine whether the use of patrons' names affects user satisfaction.

Interest was observed by using two items in the revised guidelines: focusing attention on the patron (item 2.2 in the revised guidelines) and maintaining word contact (2.6). The remaining items were excluded from coding because they were mostly applicable to the physical reference 
setting $(2.1,2.3,2.4$, and 2.5$)$, e-mail $(2.7)$, or pre-interview stage (2.8).

Listening/inquiring was observed by two behavioral types: receptive and cordial listening (3.1 and 3.2); and inquiring by rephrasing, clarifying, or asking questions (3.5-3.8). The rest of the items were excluded from coding because they were not easily observable (3.3, 3.4, and 3.9) or overlapped with other items (3.9).

Searching was observed by two behavioral types: searching for or with patrons $(4.3,4.6,4.10$, and 4.11), and offering pointers or information sources $(4.5,4.9$, and 4.11). Some behaviors, such as co-browsing, were coded as both when they involved searching and offering information sources. Four items were excluded from coding because they either pertain to listening/inquiring (4.1 and 4.2-verifying words) or follow-up (4.7), or indicate a cognitive process rather than an observable behavior (4.2 and 4.8).

Finally, follow-up was observed by three behavioral types: proper closing (4.7, 5.1, and 5.9), offering alternatives or making referral (5.4-5.8 and 5.9), and asking to come back for further assistance (5.2).

RUSA behaviors were coded by two independent coders for intercoder reliability in order to ensure the consistency. First, the primary researcher coded the entire 422 transactions. Then, the second coder, a reference librarian who received training for coding the RUSA behaviors, coded every fifth transaction $(n=84)$. This sample for intercoder reliability comprises 20 percent of the total transactions, which is the recommended percentage for social science research..$^{10}$ Finally, the percentage agreement between the two coders was calculated for each behavior, which informs the level of agreement between two coders. ${ }^{11}$ The agreements were Welcoming (91.7 percent), Use of patrons' name (96.4 percent), Interest (78.5 percent), Listening (85.6 percent), Inquiring (78.6 percent), Searching with or for patrons (76.2 percent), Offering pointers and information sources (78.6 percent), Asking if answered completely (91.7 percent), Offering referrals (85.0 percent), and Asking to come back for further assistance (90.5 percent). All these intercoder percentage agreements were either above or close to the generally acceptable threshold value of 80 percent. ${ }^{12}$

It should be noted that the use of the RUSA guidelines in the current study is differentiated from the approaches of the previous studies. ${ }^{13}$ While the earlier studies did not observe librarian behaviors with respect to actual items in the guidelines or measured with a few items only, the present study used the entirety of the items in the revised guidelines as the coding scheme to analyze librarians' chat reference behaviors.

\section{RESULTS}

\section{User Satisfaction}

User satisfaction has been one of the most frequently used outcome variables that measure reference service effectiveness. ${ }^{14}$ In the present study, user satisfaction was assessed through user responses to the following four questionnaire items: satisfaction with the answer, perceived staff quality, willingness to return to the service, and positivity of service experience. First, satisfaction with the answer was assessed by asking the question, "Were you satisfied with the answer you received to your reference question?" Figure 2 shows the distribution of the responses to this question.

Among the 417 respondents who answered this question, 65.2 percent reported that they

Figure 2. Satisfaction with the Answer

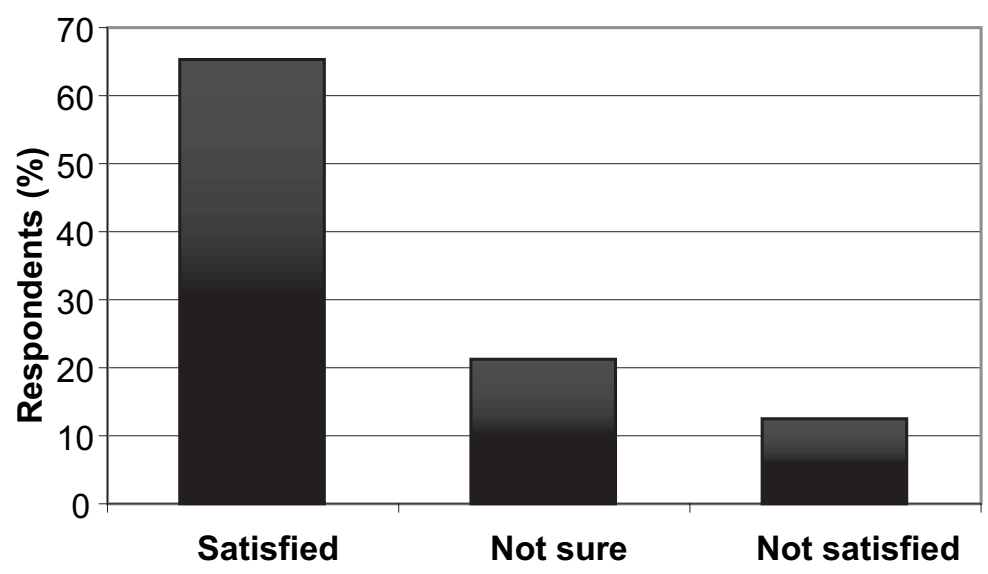

were satisfied with the answer received, and 21.1 percent of the respondents were not sure whether they were satisfied or not. Finally, 12.6 percent of the respondents reported that they were not satisfied at all.

Perceived staff quality, the second indicator of user satisfaction, was assessed by the user response to the question, "The quality of the library staff service in answering this request was. The results are presented in figure 3 .

Among the 416 people who responded, 68.2 percent of the respondents answered that the librarians handling the reference questions were excellent. About 19.5 percent evaluated the librarians' performance as good, and 11.3 percent as poor. 
Willingness to use the service again, the third indicator of user satisfaction, was measured using the questionnaire item, "Will you use this service again?" Figure 4 presents the distribution of the responses.

Among the 417 people who responded to this question, 77.2 percent answered that they were very likely to use the service again, 19.0 percent of the respondents answered maybe, and only 3.8 percent said they would never use the service again.

Regarding positivity of service experience, among the total of 422 survey responses, 183 offered open-ended comments on the service. Figure 5 represents the distribution of responses.

As shown in figure 5, 62.9 percent of the respondents evaluated the experience positively, and 28.4 percent evaluated it negatively. About 10 percent of the respondents described it as either a mixed or neutral experience. Frequently men-

Figure 3. Perceived Staff Quality

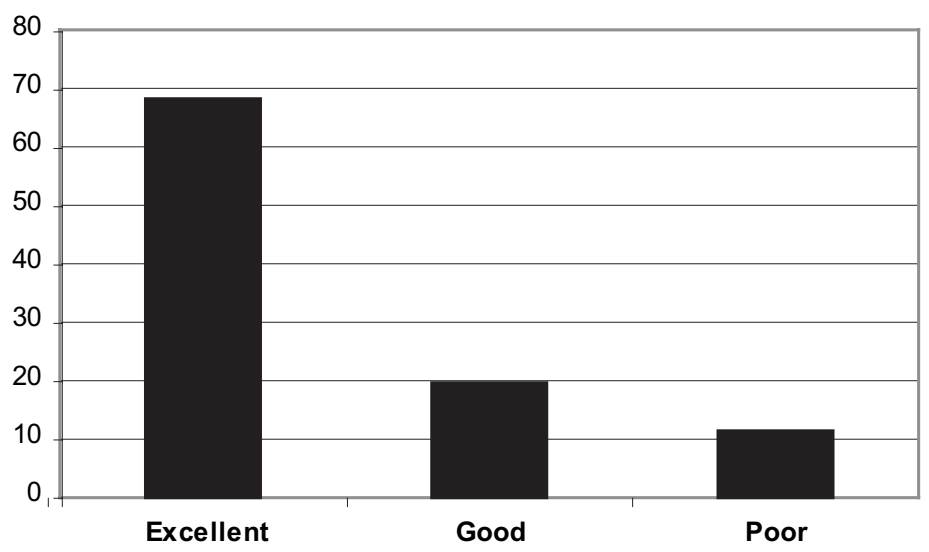

Figure 4. Willingness to Use the Service Again

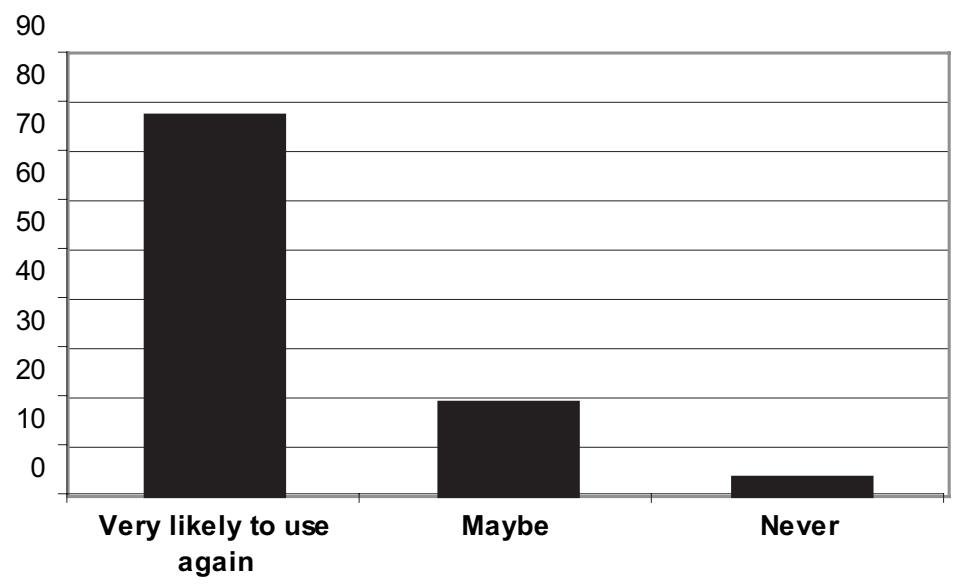

tioned expressions among the positive open-ended responses included "wonderful service," "quick," "helpful," "innovative," "cool," "good use of public money," and other comments indicating immediacy, convenience, and ease of use, including "human contact," "anytime 24/7," "likable," "interesting," and "time saver." Frequently mentioned expressions among those reporting a negative experience include "hard to use interface design," "didn't answer the question," "slow response time," "virtual librarians should access account," "virtual reference service coverage should be clearly indicated," technical problems (such as disconnections), "waiting," "service delay," misunderstanding, hasty ending, listening skill lacking, and "poor service." In addition to the patrons' negative and positive experiences expressed via the responses, mixed comments also were observed. An example of a mixed comment is "the idea of the virtual service is great but I didn't get much help." Comments that were categorized as neutral included suggestions for additional features, unawareness of the service's nationwide nature, additional information about the patrons' information needs or their background, or reports about problems experienced after the session ended.

Finally, overall user satisfaction was computed by summing up the first three questionnaire items that measured different aspects of user satisfaction. This computation was necessary because the user satisfaction items in the survey questionnaire were measured on a simple three- or four-point ordinal scale (for example, "satisfied," "not sure," and "not satisfied" for "satisfaction with the answer" item). These ordinal level measurements are not suitable for undertaking the inferential statistical tests that are crucial to answer the research questions of the present study. To resolve this problem, the three ordinal level variables were summed to create a composite variable, which increases the variability of the measure. This data management procedure allowed the researchers to conduct necessary inferential statistical tests. Survey research literature indicates that a composite variable is generally more valid and reliable than a single question item because it increases variability of the measurement. ${ }^{15}$

The transformation of the existing three questionnaire items into a composite variable involved a series of conversions from a natural language answer choice to a numeric value. By carefully analyzing the wording of the answer choices, a set of logical numeric values were assigned for answer choices of each of the three questionnaire items on the same five-point Likert scale. First, for the satisfaction with the answer item, the numeric value assigned for "unsatisfied" was 
1, 2 for "not sure," and 5 for "satisfied." For the perceived staff quality item, the value assigned for "poor" was 1, 3 for "average," 4 for "good," and 5 for "excellent." For the willingness to return item, the numeric value assigned for "never" was 1, 3 for "maybe," and 5 for "very likely." This value assignment procedure is presented in figure $6 .{ }^{16}$

In order to determine the composite variable's reliability and validity, a classical theory alpha reliability and factor analysis were performed, respectively. First, the reliability test generated a score for the sample that had a Cronbach's alpha reliability coefficient $(\alpha)$ of .845 for user satisfaction. This score is greater than the customary threshold value of .70 , indicating that the composite variable is reliable. Second, the factor analysis result showed that the three questionnaire items were loaded on one-factor solution, with factor loading scores of $.868, .916$, and .876 . All three items explained 78.64 percent of variance in the factor. This result indicates that the composite variable is measuring a single construct with a high score validity, suggesting that the composite variable is a valid measure of user satisfaction. ${ }^{17}$ The mean of the composite variable, user satisfaction, was 12.69 , with a standard deviation of 3.44 in the range between a maximum value of 3 for "highly dissatisfied" and the minimum value of 15 for "highly satisfied." This composite variable was used to examine the relationship between the use of RUSA behaviors and user satisfaction below.

\section{The Presence of RUSA Behaviors in Chat Reference Interviews}

Research question 1 of the present study asks to what extent reference staff members employ each of the ten RUSA behaviors during their chat reference transactions. Figure 7 presents the findings.

As shown in figure 7 , the presence of the ten selected RUSA behaviors ranged between 28.7 percent and 63.7 percent $(N=422)$. The three most frequently observed behaviors were comeback (63.7 percent), interest (63.0 percent), and welcoming (53.8 percent). A complete comparison of this finding with those reported in the previous studies is not feasible because none has used the complete revised guidelines as a coding scheme. A couple of studies allow a partial comparison in the area of follow-up. According to Ross and Dewdney's research, follow-up behaviors were observed in approximately one-third of the total in-person reference transactions. ${ }^{18}$ Also in the physical library setting, Gatten and Radcliff reported that 29 percent of the proxy patrons were asked by the librarians if their questions were answered. ${ }^{19}$
In the present study, however, the three follow-up behaviors appeared with greater frequency, ranging between 46.9 percent and 63.7 percent. Their

Figure 5. Positivity of User Experience

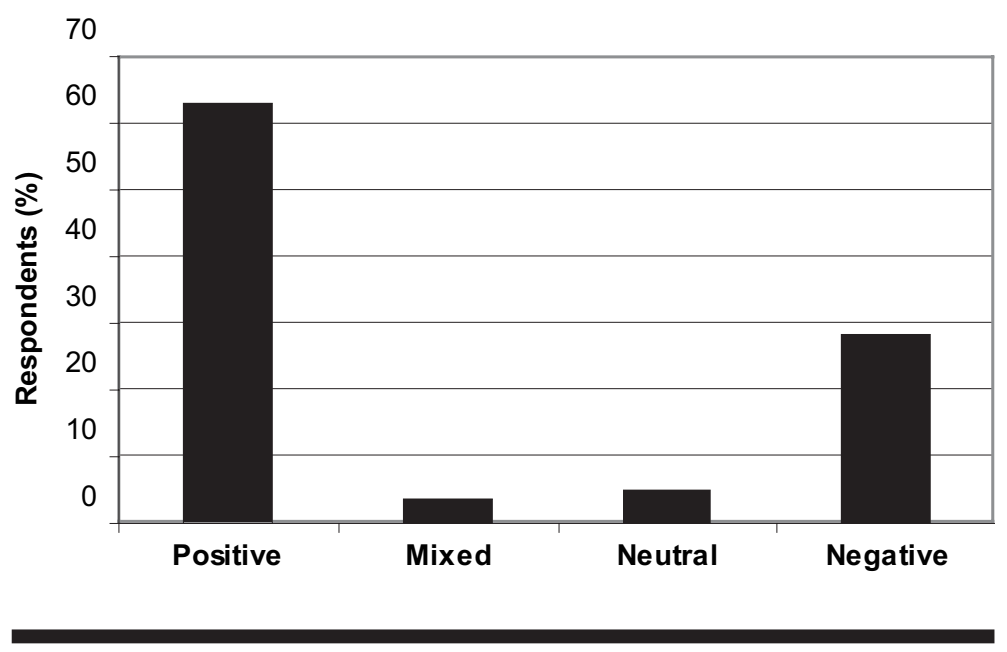

Figure 6. Three User Satisfaction Items on a Five-Point Scale

\begin{tabular}{|c|c|c|c|c|}
\hline & \multicolumn{3}{|l|}{ Negative } & \multirow{2}{*}{$\begin{array}{c}\text { Positive } \\
5\end{array}$} \\
\hline & 1 & 3 & 4 & \\
\hline 1. Satisfaction with the answer & Unsatisfied & Not sure & & Satisfied \\
\hline 2. Perceived staff quality & Poor & Average & Good & Excellent \\
\hline $\begin{array}{l}\text { 3. Willingness to use the service } \\
\text { again }\end{array}$ & Never & Maybe & & Very likely \\
\hline
\end{tabular}

Figure 7. Presence of RUSA Behaviors in Chat Reference Transactions $(\mathrm{N}=422)$

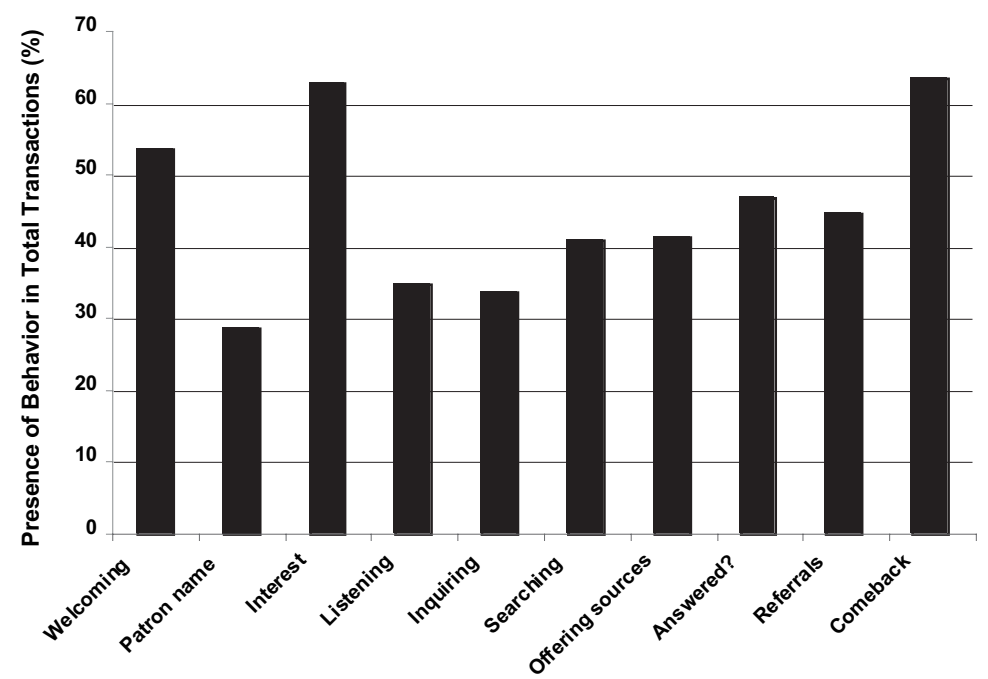


frequent appearance may reflect the use of the scripted words stored in the chat reference software program (for example, "If you need further assistance, please contact us again").

In reviewing the above findings, it should be noted that not all RUSA behaviors are expected to appear in a single reference session. For example, probing is not generally expected to occur in response to directional or circulation policy questions. Similarly, offering alternatives or making referrals are expected to occur mostly when reference staff is not able to provide a complete answer. Therefore, behaviors with a low frequency in figure 6 do not necessarily indicate inadequate behavioral performance on the part of reference staff. Rather, the information about the RUSA behaviors should be more useful in its relationship with user satisfaction, which is described below.

\section{RUSA Behaviors and User Satisfaction}

Research question 2 relates to whether chat reference users would be more satisfied with the service when librarians demonstrate a RUSA behavior than when they do not. The findings are presented in figure 8 , where the means of the user satisfaction are compared between when librarians showed the behavior and when librarians did not.

Across all but two behaviors, user satisfaction was found to be higher when librarians performed the RUSA behaviors than when they did not. A series of statistical analyses was conducted to determine the statistical significance of the difference in user satisfaction between when each RUSA behavior was present and absent. Both parametric statistics (specifically, independent two-group ttests) and non-parametric statistics (specifically, the Mann-Whitney U test) were considered in our

Figure 8. User Satisfaction with Ten RUSA Behaviors

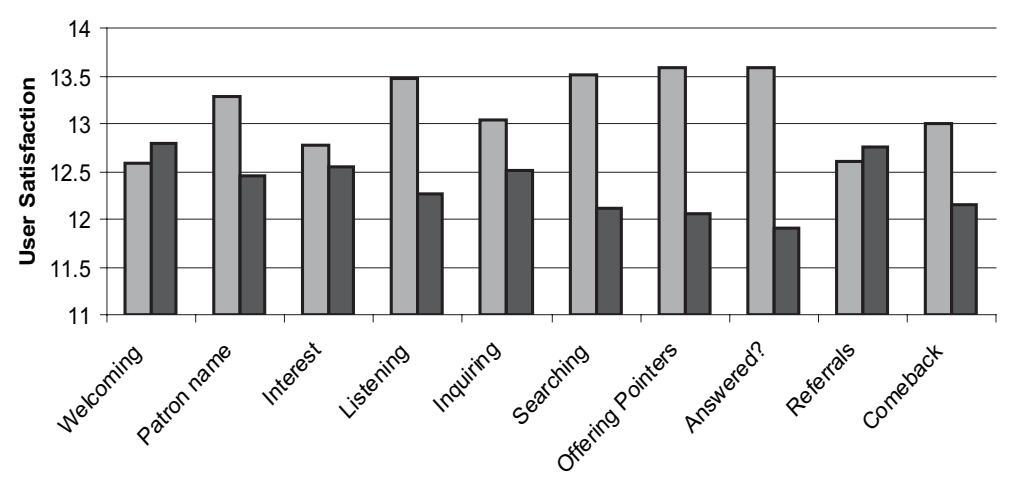

口User satisfaction when librarians showed the behavior

uUser satisfaction when librarians did NOT show the behavior study to determine the most appropriate statistical technique for the tests. In general, parametric statistics are recommended when a test variable: (1) is measured on an interval or ratio level; (2) is measured on a sample size of sixty cases or more; or (3) is normally distributed. When the data was examined with respect to these three criteria, the answer was not clear-cut. The test variable, user satisfaction, is an interval-level variable measured on the sample size of 422 , but is not normally distributed.

Hence, the data were examined using both parametric and non-parametric statistical techniques, and the test results were compared. If the two statistical techniques generate identical results, parametric statistics are recommended to present the data, which is the case in the present study. ${ }^{20}$ When tested using SPSS 14.0 , it was revealed that test results from both techniques were identical across all ten RUSA behaviors. This result indicates that the Mann-Whitney $\mathrm{U}$ test results corroborated the results from the t-tests. The findings are presented in table 1 .

As presented in table 1, user satisfaction was statistically significantly different in six out of the ten RUSA behaviors at the significance level of $\alpha$ $<.05$. Satisfaction was statistically significantly higher when reference staff showed the following six behaviors than otherwise; that is to say, chat reference services were perceived to be more satisfying to the patrons when librarians:

- used the patron's name during the reference interview;

- communicated more receptively and listened more carefully;

- searched with or for the patron;

- provided pointers;

- asked the patron whether the question was completely answered; and

- asked the patron to come back if they needed further assistance.

This result is consistent with the findings of the previous studies conducted in face-to-face reference setting, which reported the positive influence of the original guidelines on reference success. ${ }^{21}$ Thus, the findings of the present study indicate that performance of RUSA behaviors also are effective in the real-time chat reference setting.

\section{Which RUSA Behaviors Are Predictors of User Satisfaction?}

Which RUSA behaviors, if observed, could predict user satisfaction with chat reference? To answer 
this research question 3, a multivariable regression analysis was undertaken at the significance level of $\alpha<.05$. The test result revealed that five of the ten RUSA behaviors were statistically significant predictors of user satisfaction. The strongest predictor of user satisfaction among all ten behaviors was "Answered?" (for example, asking patrons if their questions have been completely answered; regression coefficient $\beta=.181, p<.001$ ), followed by "Offering Pointers" (for example, offering pointers, detailed search paths and URLs, and names of resources used to find the answer; regression coefficient $\beta=.124, p=.014$ ), "Come back" (for example, encouraging the patrons to return if they have further questions; regression coefficient $\beta=$ $.112, p=.019$ ), "Searching" (for example, searching with or for patrons by explaining search strategies and sequences and reformulating searching strategies; regression coefficient $\beta=.112, p=.023$ ), and "Listening" (for example, receptive and cordial listening; regression coefficient $\beta=.097, p=.044$ ).

\section{DISCUSSION OF RESULTS}

The present study's purpose was to expand the understanding of effective reference staff behaviors, particularly focusing on whether chat reference can be more successful when librarians employ the behaviors recommended in the revised RUSA guidelines. From the content analysis of 422 chat reference transcripts, it was found that the selected ten RUSA behaviors appeared in a range between 28.7 percent and 63.7 percent of the total transactions. In six out of ten RUSA behaviors, user satisfaction was significantly higher when librarians demonstrated those behaviors during chat sessions than when they did not. Those behaviors were: (1) use of patrons' names; (2) listening; (3) searching; (4) offering pointers; (5) asking if questions were answered; and (6) asking patrons to come back (see table 1). Furthermore, when examining the behavioral predictors of user satisfaction, five of the ten RUSA behaviors were found to be significant predictors of user satisfaction. They were: (1) asking whether the question was answered completely; (2) offering information sources; (3) asking patrons to come back when they need further assistance; (4) searching information sources with or for the patrons; and (5) listening to questions in a cordial and receptive manner. These findings indicate that behaviors recommended in the revised guidelines do, indeed, affect user satisfaction with chat reference. It confirms that the RUSA behaviors are as important in ensuring successful chat reference as they have been shown to be in the case of physical reference desk settings. The findings also suggest that the RUSA

Table 1. Comparisons of User Satisfaction between Presence and Absence of RUSA Behaviors

\begin{tabular}{|c|c|c|c|c|}
\hline \multirow[b]{2}{*}{$\begin{array}{l}\text { Ten RUSA } \\
\text { Behaviors }\end{array}$} & \multicolumn{2}{|c|}{ User Satisfaction } & & \multirow[b]{2}{*}{ Sig.(p) } \\
\hline & $\begin{array}{l}\text { When Librarian } \\
\text { Showed the Behavior }\end{array}$ & $\begin{array}{l}\text { When Librarian Did } \\
\text { Not Show the Behavior }\end{array}$ & $\begin{array}{l}\text { Difference in } \\
\text { User Satisfaction* }\end{array}$ & \\
\hline Welcoming & 12.59 & 12.80 & -0.21 & .539 \\
\hline Patron name & 13.29 & 12.45 & 0.84 & $.014^{* *}$ \\
\hline Interest & 12.78 & 12.54 & 0.24 & .488 \\
\hline Listening & 13.47 & 12.27 & 1.2 & $.000^{\dagger}$ \\
\hline Inquiring & 13.04 & 12.51 & 0.53 & .111 \\
\hline Searching & 13.51 & 12.12 & 1.39 & $.000^{\dagger}$ \\
\hline Offering Pointers & 13.59 & 12.05 & 1.54 & $.000^{\#}$ \\
\hline Answered? & 13.58 & 11.90 & 1.68 & $.000^{\#+}$ \\
\hline Referrals & 12.61 & 12.76 & -0.15 & .653 \\
\hline Come back & 13.00 & 12.15 & 0.85 & $.019 *$ \\
\hline
\end{tabular}

"Difference in User Satisfaction = User Satisfaction when behavior shown - User Satisfaction when behavior not shown. For a particular behavior compared, a positive value indicates that user satisfaction is higher when the behavior was shown than not shown. Independent samples t-test results showed that the use of RUSA behaviors resulted in higher user satisfaction in the seven behaviors marked at the significance level of $\alpha<.05$ ("ip $<.001 ;{ }^{\dagger} \mathrm{p}<.01$; and ${ }^{* *} \mathrm{p}<.05$ ). 
guidelines continue to constitute a pertinent assessment tool for chat reference service.

The results of this study suggest how each area in the revised guidelines could be further developed. First, in approachability (Area 1), the coding process revealed that most behavior items in the revised guidelines were not observable through chat transcripts. Other than the scripted words indicating initial welcoming word contact (for example, "Hi, this is the reference librarian"), the transcripts did not have many expressions indicating approachability behaviors. Most items listed under approachability either relate to the pre-interview stage (such as informative signage) or lack explicit verbal indicators that help us code the transcripts for approachability as behaviors. Therefore, the finding that approachability has little influence on user satisfaction should be interpreted with caution. This problem in the coding process suggests that the revised guidelines need to incorporate clearer behavioral indicators of approachability in order to encourage reference staff to use more explicit welcoming gestures to the patrons and to make the revised guidelines a true behavioral assessment tool. The influence of approachability on user satisfaction should be reassessed with those new behavioral indicators in future studies.

A similar contention can be made with regard to interest, the second area of the revised guidelines. Behavioral indicators of interest in text-based environments include librarians' attention to the patron and maintaining or re-establishing word contact by sending written or prepared prompts and so forth. In the current study, interest was mostly captured in scripted words, such as "I'm reading your question. Just a moment please." Observations of behaviors via transcripts demonstrated limitations in capturing librarians' interest in answering questions. This limitation may have affected the lack of association of interest with user satisfaction in this study.

Listening/inquiring (Area 3) has been regarded among librarians as a core component of the successful reference interview. ${ }^{22}$ Consistent with previous findings, this study also found that user satisfaction was higher when librarians demonstrated listening behaviors than when they did not. Cordial and receptive listening also was found to be a significant positive predictor of user satisfaction. However, in this study, we found inquiring (or probing behavior) was not associated with user satisfaction. As a viable explanation for this finding, it is conjectured that these probing behaviors do not guarantee the actual answer that the service users are ultimately interested in receiving. It also is possible that probing behaviors may be more important in a face-to-face reference interview, whereas online reference users may, by contrast, only be interested in a specific answer, as the medium of the Web tends to attract users with the promise of an immediate answer.

Searching, the fourth area of the revised guidelines, was observed by two types of behaviors, "searching with or for patrons" and "offering pointers and information sources." User satisfaction was higher when these two searching behaviors appeared in the transcripts. Both behaviors were revealed to be important positive predictors of user satisfaction. Indeed, this finding indicates that user satisfaction is directly associated with actual searching activities and tangible answers that can resolve patrons' problems.

Follow-up, the fifth area of the revised guidelines, was observed in three types of behaviors. Interestingly, two of the three follow-up behaviors were found to be strong positive predictors of user satisfaction. According to our findings, user satisfaction was most strongly predicted by the simple behavior of asking follow-up questions, such as "Did you find what you needed?" "Does this completely answer your question?" or "Is there anything else I can help you with?" Certainly, this finding is not unprecedented. Gers and Seward contended that follow-up is "the single most important behavior because it has the potential for allowing one to remedy lapses in other desirable behaviors." ${ }^{23}$ As Dewdney and Ross maintained, asking follow-up questions is a chance to "repair the interaction or to formulate a new, more promising search strategy," but reference staff members tend to make referrals as a way of circumventing the reference interview. ${ }^{24}$ If such a case, avoidance certainly would not satisfy many users.

It should also be noted that two follow-up questions ("asking if the question was answered" and "asking to come back for further assistance") were not significantly correlated with each other, and each behavior increased user satisfaction independently. This finding implies that these are two quite different questions; thus, librarians should make sure to ask both questions before closing their transaction.

One follow-up behavior, "providing referrals/ alternatives," did not increase user satisfaction in our study. This may be because users are rarely satisfied with "delayed" answers, but defer their assessment of satisfaction until they obtain the tangible answer they are seeking. This finding is consistent with the findings of Dewdney and Ross, who reported the ineffectiveness of unmonitored referrals at physical reference desks. ${ }^{25}$ This find- 
ing about referrals indicates that reference staff should make a referral only when they deem it necessary rather than using it as a good alternative to an answer.

\section{CONCLUSION}

By adopting the revised guidelines as a behavioral performance assessment tool, the present study revealed that many behaviors they prescribed are effective in enhancing user satisfaction with chat reference service. This study also attempted to explain why certain behaviors in the revised guidelines were not related to satisfaction, as discussed in the findings. Combined, the results of the present study offer many implications for reference service practitioners, for the researchers investigating various phenomena in virtual reference services, and for the developers at RUSA working on future revisions of the revised guidelines.

First, the results of this study could be of significant assistance to staff training in the chat reference service practice. Consistent with the findings of the studies conducted in the physical reference setting, the results of this study also indicate that follow-up behaviors should continue to be emphasized in staff training in the chat reference environment as a way to enhance both staff performance and user satisfaction.

The present study also identifies places for future adjustments of the revised guidelines. As pointed out earlier, some items in the behavioral guidelines were not readily observed as an explicit behavior, while other items were not located in the proper category across the five areas. These items need further clarification if the revised guidelines are to be adopted by reference librarians as a practical behavioral evaluation tool that can be used with few modifications. In addition, inclusion of specific behavioral examples for each item would be very useful, especially in the areas of interest and listening/inquiring. A future study could assess these areas utilizing further development of the guidelines.

Despite efforts to make this study as rigorous as possible, it is not without limitations and thus calls for further research. First, user satisfaction was examined as a way to investigate the effectiveness of chat reference services in the present study. Considering that user satisfaction is just one aspect of service effectiveness, researchers could employ other indicators of service effectiveness, such as answer accuracy or answer completeness. Another limitation is the fact that this study was conducted in a single public library system, although the observed librarians were from forty-nine library systems participating in a nationwide collaborative chat reference program. It also should be noted that the current study observed only 30.4 percent of the total 1,387 analyzable transactions. People who took the time to answer the online pop-up survey might not constitute an accurate representation of the entire user population of the chat reference service. Thus, our findings should be further confirmed by replicating this study in libraries of different types and sizes and by enhancing the sampling technique.

Finally, this study examined the usefulness of the revised guidelines by observing the use of chat reference only. Nonetheless, the revised guidelines were developed to encompass various modes of virtual references, and thus similar studies should be conducted for other modes, such as e-mail and instant messenger, in order to develop further recommendations for the revised guidelines.

Despite the limitations mentioned above, the results of this study will encourage RUSA's further promotion and perhaps enhancement of the revised guidelines. This was the first empirical study that investigated the revised guidelines' value by assessing its actual items in the chat reference setting. By revealing the positive influences of the RUSA behaviors on user satisfaction, the present study demonstrated that the revised guidelines are effective behavioral standards for librarians' real-time chat reference interviews. Thus, by incorporating the recommendations of this study, RUSA could further promote the revised guidelines as a practical reference staff training and assessment tool.

\section{References and Notes}

1. Julie Arnold and Neal Kaske, "Evaluating the Quality of a Chat Service," portal: Libraries and the Academy 5 (Apr. 2005): 177-93; Steve Coffman and Linda Arret, "To Chat or Not to Chat-Taking Another Look at Virtual Reference, Part I," Searcher 12, no. 7 (July/ Aug. 2004): 38-46; Steve Coffman and Linda Arret, "To Chat or Not to Chat-Taking Another Look at Virtual Reference, Part II," Searcher 12, no. 8 (Sept. 2004): 49-56; Abby Kasowitz, Blythe Bennett, and R. David Lankes, "Quality Standards for Digital Reference Consortia," Reference \& User Services Quarterly 39, no. 4 (2000): 355-63; Julie Kibbee, David Ward, and Wei Ma, "Virtual Service, Real Data: Results of a Pilot Study," Reference Services Review 30, no. 1 (2002): 25-36; Diane Nester Kresh, "Offering High Quality Reference Service on the Web: The Collaborative Digital Reference Service (CDRS)," D-Lib Magazine 6 no. 6 (June 2000), www.dlib.org/dlib/ june00/kresh/06kresh.html (accessed Aug. 1, 2005); Diane Kresh, "High Touch or High Tech: The Collaborative Digital Reference Service As a Model for the Future of Reference," Advances in Librarianship 26 (2002): 149-73; Jana Ronan and Carol Turner, Chat Reference: A SPEC Kit, Spec Kit 273 (Washington D.C.: 
Association of Research Libraries, 2002); Bernie Sloan, "Collaborative Live Reference Services," www.lis.uiuc. edu/ b-sloan/collab.htm (accessed July 7, 2005); Jo Bell Whitlatch, "Reference Service Effectiveness," RQ 30 (Winter 1990): 205-20.

2. Reference and User Services Association, "Guidelines for Behavioral Performance of Reference and Information Service Providers," rev. June 2004, www.ala. org/ala/rusa/rusaprotools/referenceguide/guidelinesbehavioral.htm (accessed Aug. 1, 2005).

3. "Guidelines for Behavioral Performance of Reference and Information Services Professionals," Reference \& User Services Quarterly 36, no. 2 (1996): 200-03

4. Jeffrey N. Gatten and Carolyn J. Radcliff, "Assessing Reference Behaviors with Unobtrusive Testing," in Library Evaluation: A Casebook and Can-Do Guide, eds. Danny P. Wallace and Connie Van Fleet, 105-15 (Englewood, Colo.: Libraries Unlimited, 2001); Matthew L. Saxton, "Evaluation of Reference Service in Public Libraries Using a Hierarchical Linear Model: Applying Multiple Regression Analysis to a MultiLevel Research" (Ph.D. diss., University of California, Los Angeles, 2000).

5. Ralph Gers and Lillie J. Seward, "Improving Reference Performance: Results of a Statewide Study," Library Journal 110 (Nov. 1, 1985): 32-35.

6. Saxton, "Evaluation of Reference Service."

7. Gatten and Radcliff, "Assessing Reference Behaviors"; Mathew L. Saxton and John V. Richardson, Understanding Reference Transactions: Transforming an Art into a Science (San Diego: Academic Pr., 2002).

8. Ian J. Lee, "Do Virtual Reference Librarians Dream of Digital Reference Questions?: A Qualitative and Quantitative Analysis of Email and Chat Reference," Australian Academic \& Research Libraries 35, no. 2 (2004): 95-110; Joseph E. Straw, "A Virtual Understanding: The Reference Interview and Question Negotiation in the Digital Age," Reference \& User Services Quarterly 39, no. 4 (2000): 376-79; Carol Tenopir, "Chat's Positive Side," Library Journal 129 (Dec. 15, 2004): 42

9. International Federation of Library Associations and Institutions, Reference and Information Services Section, "IFLA Digital Reference Guidelines," www.ifla.org/VII/s36/pubs/drg03.htm (accessed Aug. 19, 2005)

10. Kimberly A. Neuendorf, The Content Analysis Guidebook (Thousand Oaks, Calif.; Sage, 2000).

11. Suzanne Bakken et al., "Evaluation of the Clinical LOINC Semantic Structure As a Terminology Model for Standardized Assessment Measures," Journal of the American Medical Informatics Association 7 (Nov/Dec. 2000): 529-38.

12. Morton Hunt, How Science Takes Stock: The Story of Meta-analysis (New York: Russell Sage Foundation, 1997).

13. Gatten and Radcliff, "Assessing Reference Behaviors"; Saxton, "Evaluation of Reference Service."

14. Ethel Auster, "User Satisfaction with the Online Negotiation Interview: Contemporary Concern in Tradi- tional Perspective," RQ 23 (1983): 47-59; George D'Elia and Sandra Walsh, "User Satisfaction with Library Service-A Measure of Public Library Performance?" Library Quarterly 53 (1983): 109-33; Joan Durrance, "Reference Success: Does the 55 Percent Rule Tell the Whole Story?" Library Journal 114 (Apr. 15, 1989): 31-32; Kirsti Nilsen, "The Library Visit Study: User Experiences at the Virtual Reference Desk," Information Research 9, no. 2 (Jan. 2004), available at: http://InformationR.net/ir/9-2/paper171. html (accessed Aug. 1, 2005); Saxton and Richardson, Understanding Reference Transactions; Jo Bell Whitlatch, "Client/Service Provider Perceptions of Reference Service Outcomes in Academic Libraries: Effects of Feedback and Uncertainty" (Ph.D. diss., University of California, Berkeley, 1987).

15. Robert F. DeVellis, Scale Development: Theory and Applications (Newbury Park, Calif.: Sage, 1991).

16. A numeric value on the five-point scale was assigned to each of the verbal descriptors in the three questionnaire items. To minimize the arbitrariness in assigning numeric values to the verbal descriptors, two alternative scales (such as four- and six-point scales) also were employed in addition to the selected five-point scale by making slight variations in the value assignment. When the test results from a series of statistical analyses for research question 2 and research question 3 were compared for all three scales to examine the stability of the assigned values, the test results were identical across all three scales, indicating the value assignment on the five-point scale is stable and reliable.

17. Jum C. Nunnally, Psychometric Theory, 2d ed. (New York: McGraw-Hill, 1978).

18. Catherine Sheldrick Ross and Patricia Dewdney, "Negative Closure: Strategies and Counter-Strategies in the Reference Transaction," Reference \& User Services Quarterly 38, no. 2 (1998): 151-63.

19. Gatten and Radcliff, "Assessing Reference Behaviors."

20. Rae R. Newton and Kjell Erik Rudestam, Your Statistical Consultant: Answers to Your Data Analysis Questions (Thousand Oaks, Calif.: Sage, 1999).

21. Gatten and Radcliff, "Assessing Reference Behaviors"; Saxton, "Evaluation of Reference Service."

22. Ethel Auster and Stephen Lawton, "Search Interview Technique and Information Gain As Antecedents of User Satisfaction with Online Bibliographic Retrieval," Journal of the American Society for Information Science 35 (1984): 90-103; Gatten and Radcliff, "Assessing Reference Behaviors"; Catherine Sheldrick Ross, Kirsti Nilsen, and Patricia Dewdney, Conducting the Reference Interview (New York: Neal-Schuman, 2002).

23. Gers and Seward, "Improving Reference Performance," 34

24. Patricia Dewdney and Catherine S. Ross, "Flying a Light Aircraft: Reference Service Evaluation from a User's Viewpoint," RQ 34, no. 2 (1994): 227.

25. Ibid., 217-30. 